Claudio Cezar Peres ${ }^{1}$

Airton Marinho-Silva ${ }^{2}$

Elizabete Cavalcante-Fernandes ${ }^{3}$

Lys Esther Rocha ${ }^{4}$

\section{Uma construção social: o anexo da norma brasileira de ergonomia para o trabalho dos operadores de telemarketing}

\author{
A social construction process of the attach- \\ ment to the Brazilian government ergonomic \\ regulation for telemarketing operators' work
}

${ }^{1}$ Ministério do Trabalho e Emprego, Delegacia Regional do Trabalho do Rio Grande do Sul, Rio Grande do Sul, Brasil.

${ }^{2}$ Ministério do Trabalho e Emprego, Delegacia Regional do Trabalho de Minas Gerais, Minas Gerais, Brasil.

${ }^{3}$ Ministério do Trabalho e Emprego, Delegacia Regional do Trabalho do Rio de Janeiro, Rio de Janeiro, Brasil.

${ }^{4}$ Ministério do Trabalho e Emprego, Delegacia Regional do Trabalho de São Paulo, São Paulo, Brasil.

\begin{abstract}
Resumo
O número de operadores das centrais de atendimento telefônico está em franca expansão no Brasil e no mundo, envolvendo cerca de 550 mil trabalhadores em nosso país. Este artigo aborda a ação coletiva em busca de melhores condições de trabalho para esses operadores, desencadeada por solicitações de intervenção ao Ministério do Trabalho e Emprego (MTE) feitas por trabalhadores portadores de Distúrbios Osteomusculares Relacionados ao Trabalho (DORT), diretamente, e por meio de seus sindicatos no Brasil. Além de ações de fiscalização sobre as empresas de telemarketing no sentido da regulação das condições de trabalho nesse setor, a Comissão Nacional de Ergonomia (CNE) do MTE, entre 2000 e 2005, organizou eventos reunindo profissionais de instituições de pesquisa, representações patronais e de trabalhadores, fazendo estudos aprofundados sobre esse tipo de trabalho. Capacitou, ao mesmo tempo, auditores fiscais do trabalho para fiscalização em ergonomia aplicada em todo o país. Essas ações resultaram na constituição de um grupo de trabalho interinstitucional em 2004 e na publicação da Recomendação Técnica 1 pelo Departamento de Segurança e Saúde no Trabalho em 2005. Enfrentando resistência empresarial e diversas inconsistências do próprio movimento sindical, visando à promulgação de uma Norma Regulamentadora para o telemarketing, o MTE constituiu um grupo técnico para a elaboração da proposta de Anexo à Norma Regulamentadora 17 ("Ergonomia”). Este artigo relata o processo de construção social dessa normatização, suas propostas e desafios.
\end{abstract}

Palavras-chaves: centrais de atendimento, operadores de telemarketing, telefonia, ergonomia, normas técnicas.

\begin{abstract}
The number of call centers is increasing in the world and in Brazil. In our country it involves around 550000 workers. This article narrates a collective action for better conditions for work of telemarketing operators in Brazil, based on diseased operators' and the Union's requests to the Brazilian Ministry of Labor and Employment (MTE). Those workers have Work Related Musculoskeletal disease. In addition to inspecting telemarketing companies to assess work conditions, the National Commission on Ergonomics of MTE, between the years 2000 and 2005, organized events joining professionals of research institution from universities, employer representatives, and workers representatives (Unions) to study issues related to this activity. At the same time, this Commission prepared the inspectors of the MTE, in all country, to proceed ergonomic evaluations. All these resulted in 2004 on a work group composed by various interested public institutions and in the year 2005 in a Proposal of a Technical Recommendation $n^{\circ} 1$ to be applied to telemarketing operators, elaborated by the Department of Labor Health and Safety (DSST/ MTE). The Brazilian's Ministry of Labor and Employment, facing employers' resistance against a governmental regulation for telemarketing activity and also Unions' inconsistencies, created a technical group to elaborate a proposal of an attachment for the regulation $n^{\circ} 17$ ("Ergonomics"). This article registers the process of social construction of this regulation, its intention and challenges.
\end{abstract}

Keywords: call centers, telemarketing operators, occupational diseases, ergonomics, technical regulations 


\section{Introdução}

As centrais de teleatendimento ou telemarketing são geralmente denominadas em linguagem empresarial como call centers. São empresas especializadas prestadoras de serviços nessa modalidade ou setores internos de empresas diversas em que os trabalhadores utilizam telefone e computadores para estabelecer comunicação com clientes ou com a população usuária de serviços públicos e privados. Inúmeros ramos da economia atual estão envolvidos: telefonia, serviços de utilidade pública, bancos, indústrias, comércio, entre outros.

O setor de call center empregava cerca de um milhão e meio de europeus e cinco milhões de pessoas nos Estados Unidos da América (EUA) em 2002 (TOOMINGAS, et al. 2002). Os dados brasileiros não diferem desses quanto à constatação de forte expansão e da sua importância econômica. Segundo a Associação Brasileira de Telemarketing, o setor vem se expandindo em altas taxas, tornando-se "um dos maiores empregadores do país", estimando-se a cifra de "mais de 555.000 empregos diretos" (ABT, 2005).

Diversas entidades sindicais e associações de trabalhadores procuraram o Ministério do Trabalho e Emprego no decorrer dos últimos anos buscando apoio e ações de fiscalização para atender às queixas de seus associados. Vários trabalhos científicos nacionais e internacionais, como Assunção e Vilela (2004), Glina e Rocha (2003), CFDT (2002), entre outros, confirmam as queixas recebidas relativas a vários tipos de adoecimento no trabalho. Esses relatos demonstram sofrimento dos trabalhadores relativos a Distúrbios Osteomusculares Relacionados ao Trabalho (DORT), problemas vocais, problemas auditivos e adoecimentos de ordem mental e psicológica. Várias pesquisas também demonstraram grande rotatividade dos trabalhadores nos empregos que utilizam, em grande escala, trabalhadores jovens e do sexo feminino, como mostraram, entre outros, Marinho-Silva (2004) e INRS (2005).

No Brasil, desde 1944, o desgaste da atividade da telefonista foi reconhecido pela legislação (artigos 226 a 230 da Consolidação das Leis do Trabalho) mediante jornadas reduzidas e obrigação de pausas, legislação essa confirmada pelo Enunciado do Tribunal Superior do Trabalho (TST), $\mathrm{n}^{\circ} 178$, para todos os trabalhadores em atividade de telefonia, como é o caso do telemarketing (PERES, 2003). Entretanto, o poder público encontra limites de intervenção, uma vez que a legislação trabalhista não provê subsídios precisos e claros sobre o trabalho em teleatendimento, especialmente a Norma Regulamentadora 17 (NR-17), sobre Ergonomia, promulgada em 1990 (MARINHO-SILVA, 2004).

Este estudo faz sucinta revisão bibliográfica dos problemas gerados pelo trabalho em teleatendimento, expõe as principais características do trabalho dos operadores, relata os passos históricos das ações do Ministério do Trabalho e Emprego e sua Comissão Nacional de Ergonomia para regulamentação do setor e discute os desafios e as dificuldades encontradas nessa construção social no momento atual.

\section{O trabalho em teleatendimento/telemar- keting}

Os serviços prestados compreendem o fornecimento de informações a público ou clientes das empresas, recebimento de reclamações, venda e assistência técnica de produtos, entre outros. É a característica da empresa principal que determina o conteúdo do trabalho dos "operadores de telemarketing”, que é a denominação usual dada aos trabalhadores nestes serviços no Brasil e adotada pela Classificação Brasileira de Ocupações $^{5}$.

Essa forma de comunicação pode envolver clientes e usuários locais ou de outras cidades, estados ou mesmo países. Pode-se fazer uma divisão ampla da atividade em telemarketing "ativo" e "passivo": no primeiro, o operador tem como função a procura de clientes, geralmente para venda de produtos e pesquisas, enquanto que, no "passivo", o trabalhador recebe chamadas telefônicas e procura resolver a demanda, que envolve reclamações, solicitações, pedidos de orientações, entre outros.

A conexão com os clientes costuma ser feita de forma automática, com a imediata distribuição das chamadas entre os operadores por um sistema informático, sem a possibilidade de controle pelos operadores do tempo entre os atendimentos (VILELA \& ASSUNÇÃO, 2004).

Os sistemas informáticos utilizados registram o tempo de atendimento de cada 
chamada e calculam médias por operador. Os trabalhadores precisam manter o padrão estabelecido pela empresa de número de chamadas e tempo médio de duração dos atendimentos, sob pena de sanções disciplinares. Os períodos utilizados pelos trabalhadores para necessidades pessoais, quando estão desconectados do sistema informático, são também registrados, devendo adequar-se a exigências preestabelecidas (BARRETO, 2001).

Existe também a escuta em tempo real e/ou a gravação dos diálogos, chamados "monitoramento", por parte dos supervisores, em que o conteúdo das conversas entre os operadores e os clientes é avaliado quanto ao cumprimento das regras e procedimentos pré-determinados, incluindo cortesia e qualidade de atendimento prestado. É proibido ao operador irritar-se ou responder com descortesia ao cliente, trazendo constantemente o trabalho sob condições estressantes, o que a literatura tem demonstrado que pode resultar em adoecimentos físico e mental.

A utilização de parâmetros estritos de controle sobre tempo, número e forma de atendimento somente é possível devido ao monitoramento eletrônico da atividade que as empresas tentam justificar com afirmativas de que os indicadores facilitariam o dimensionamento da central de atendimento, inclusive para atender metas da Agência Nacional de Telecomunicações. Não se considera, no entanto, as possíveis repercussões sobre a saúde dos seus empregados. Encontram-se, com freqüência, campanhas para estímulo constante e permanente da competição entre os empregados para o atendimento de metas pré-determinadas de produção, com divulgação de nomes e desempenho dos operadores para os demais colegas. É costumeiro que sejam afixados avisos alertando o operador de que será eliminado se não observar essas metas.

\section{As repercussões na saúde dos trabalhado- res em telemarketing}

De maneira análoga às queixas apresentadas por organizações de trabalhadores ao Ministério do Trabalho e Emprego, os estudos sobre as repercussões na saúde dos operadores têm demonstrado sofrimento mental, DORT e alterações vocais, como se relata a seguir.

Em relação ao sofrimento mental, estudos realizados, ainda em 1910, por Julliard, levaram à criação da expressão "neurose das telefonistas", a partir de sintomas de fadiga, tensão nervosa, cefaléias, insônias, dificuldades para refletir e para fixar sua atenção e "violento nervosismo". Em 1956, foi publicado o clássico estudo sobre a "Neurose das Telefonistas", destacando dois elementos fundamentais para o adoecimento, entre outros: a exigência de rendimento e o controle no trabalho (LE GUILLANT et al., 1984).

Dejours (1992), ao analisar o trabalho das telefonistas, afirma que o sofrimento mental aparece como intermediário necessário à submissão do corpo. Da mesma forma, o autor salienta haver uma contradição entre um serviço destinado à comunicação e a proibição de qualquer relação psicoafetiva, já que é proibido se expressar e passar, nas respostas ao interlocutor, qualquer parcela de desejo próprio.

Sobre a densidade do trabalho das telefonistas, Wisner (1994) constata que é queixa corrente das telefonistas o intenso esforço mental necessário em razão do número de operações a realizar simultaneamente.

No Brasil, vários autores, como Assunção e Souza (2000), Abrahão (2000), Fernandes (2002), Glina e Rocha (2003), descreveram os fatores de estresse no trabalho e repercussões sobre a saúde mental do trabalho das telefonistas e operadores de telemarketing.

Quanto aos DORT, o trabalho em telemarketing envolve a utilização intensiva de microcomputadores, permitindo grande intensificação do trabalho e agregando riscos associados ao trabalho com computadores às exigências mentais e comunicacionais características das tarefas desses trabalhadores.

Estudos sobre prevalência de sintomas entre os trabalhadores de centrais de atendimento vêm sendo realizados em diferentes países. No estudo da Confederação Sindical Francesa (CFDT, 2002), verificou-se a prevalência de ansiedade, estresse e fadiga em $71 \%$ dos operadores pesquisados, além de problemas visuais e auditivos em 16\% e dorsalgias em 6\% dessa população.

Vários estudos relacionam sintomas osteomusculares dos ombros, pescoço e membros superiores com o aumento de pressão gerencial e de carga de trabalho, incluindo rotinas de trabalho com poucas oportunidades de tomada de decisões, altas demandas de processamento de in- 
formações, posturas desconfortáveis pelo mobiliário, temperaturas inadequadas e número reduzido de pausas (HALES et al., 1994; HOEKSTRA et al., 1995; ROCHA et al., 2005; FERREIRA \& SALDIVA, 2002).

Outros estudos mostram problemas vocais em operadores de teleatendimento (UNISON, 2005; CFDT, 2002; OGREN et al., 2001).

\section{Estratégia metodológica}

Decidiu-se por um formato metodológico de descrição, relatos e análise qualitativa para trazer material para a discussão dos desafios e das necessidades de regulamentação pública das condições de trabalho nesse setor no Brasil. Trata-se de análise descritiva, utilizando dados da bibliografia pesquisada e documentos públicos recentes da Inspeção do Trabalho sobre o tema de teleatendimento.

Analisou-se o conteúdo de atas de reuniões da Comissão Nacional de Ergonomia do período de 2001 a 2004 e atas de reuniões realizadas entre setembro e novembro de 2004 pelo Grupo de Trabalho Interministerial para Teleatendimento, que envolveu representantes do Ministério da Saúde, do Ministério da Previdência Social, do Ministério Público do Trabalho e da Agência Nacional de Telefonia, a ANATEL.

Além disso, foram analisados relatórios de inspeções dos auditores fiscais do trabalho realizadas em centrais de atendimento
Broughton e Patel (2003) relataram sintomas relacionados à exposição aguda a "choques acústicos" em operadores de telemarketing na Austrália, causados por ruídos de alta freqüência e intensidade, tais como sensações de parestesia ao redor da orelha, perda de audição, zumbido no ouvido afetado, alterações do equilíbrio, dores recorrentes, ansiedade, depressão e episódios de síndrome do pânico.

telefônico nos estados de São Paulo, Minas Gerais, Rio de Janeiro e Rio Grande do Sul, bem como registros dos eventos "Novas atividades e velhas doenças: o trabalho em teleatendimento", painel realizado em 30 de setembro de 2002, em Porto Alegre, e "Seminário Nacional sobre a Atividade de Teleatendimento/Telemarketing no setor de telefonia”, realizado em São Paulo, em outubro de 2002. Ambos os eventos envolveram representantes de trabalhadores, empregadores, governo e órgãos de pesquisa e ensino.

Também foi estudado o processo resultante de solicitação da Federação Interestadual dos Trabalhadores em Empresas de Telecomunicações (FITTEL), protocolado no MTE sob n ${ }^{\circ}$ 46010.000880/2002-76, ao Departamento de Segurança e Saúde no Trabalho para que fosse designada comissão tripartite para regulamentação das condições de trabalho em teleatendimento e para atualização da Norma Regulamentadora 17, sobre Ergonomia.

\section{Dados e relatos obtidos das inspeções realizadas pela auditoria do trabalho}

Nos últimos anos, vêm sendo realizadas inspeções em empresas de teleatendimento/telemarketing pelas delegacias regionais do trabalho em todo o Brasil, relatando-se neste estudo as experiências dos autores relativas ao Rio Grande do Sul, Minas Gerais, São Paulo e Rio de Janeiro. Os resultados são muito semelhantes nas observações sobre as situações de trabalho e nas inconformidades verificadas, apesar das distâncias geográficas.

Dos relatórios de fiscalização do Ministério do Trabalho e Emprego (MTE) percebe-se o grande número de empregados do setor, pois apenas uma das grandes empresas de teleatendimento em uma das capi- tais brasileiras empregava, em dezembro de 2005, cerca de 8.000 trabalhadores.

Observa-se forma homogênea de organização do trabalho entre as empresas, com intenso monitoramento eletrônico das atividades, critérios de avaliação de desempenho conflitantes entre si e ambigüidade de tarefas. As metas de trabalho são exigentes, com interposição de artifícios para aumento de produtividade, como prêmios por produção e competição entre equipes. Há numerosas queixas de adoecimentos físico e mental e, inclusive, de discriminação de trabalhadores que não atinjam suas metas, alocados em "células de rejeitados". As pausas são restritas ao mínimo legal, em 
sua maioria, havendo inclusive controle das pausas para atendimento às necessidades fisiológicas.

Como regra geral, as fiscalizações observaram pouco cuidado nessas empresas em relação aos aspectos preventivos, incluindo Programas de Controle Médico de Saúde Ocupacional que não abordam efetivamente os riscos existentes nas tarefas, especialmente aqueles relativos a distúrbios osteomusculares, vocais e auditivos. As doenças surgidas vêm sendo tratadas como doenças não ocupacionais, sendo raras as emissões, pelas empresas e seus médicos, de Comunicações de Acidente de Trabalho, forma correta de notificação desses agravos ao poder público. Essas comunicações terminam por serem emitidas pelo sindicato da classe trabalhadora, gerando discussões prolongadas em nível previdenciário e judicial. Os Programas de Prevenção de Riscos Ambientais das empresas fiscalizadas têm se limitado a aprovar as instalações existentes, deixando de apontar questões críticas a serem corrigidas, como, por exemplo, condições de climatização e ruído (ambiental ou no interior dos fones de ouvido). As análises ergonômicas das situações de trabalho apresentadas também se mostraram como documentos de aprovação do mobiliário utilizado, mesmo que não adequado, sem discutir a organização do trabalho, os métodos de controle, a intensificação das tarefas, trabalho noturno e em turnos.

Outros problemas apontados nas fiscalizações dizem respeito ao restrito fornecimento de água potável, fundamental para a saúde vocal, e ao aspecto do tempo para atendimento das necessidades fisiológicas resultantes da ingestão de líquidos, assim como ao dimensionamento insuficiente de áreas de vivência, prejudicando o repouso adequado nas poucas pausas existentes no trabalho.

Além dos aspectos de segurança e saúde no trabalho, foram detectadas também irregularidades quanto ao não registro formal de empregados, ao número insuficiente de operadores em relação ao crescimento da produção das centrais, ao repouso semanal não respeitado, às jornadas de trabalho estendidas ilegalmente e à utilização precária de trabalho terceirizado.

Confirmam-se, com as fiscalizações, as várias publicações, já citadas, quanto a índices elevados de absenteísmo e de rotatividade (turnover) da mão-de-obra, além de diversos afastamentos de trabalhadores em benefício previdenciário, o que não seria esperado tendo em vista a juventude dos trabalhadores do setor.

Na tentativa de controle desses parâmetros que prejudicam a produção das empresas, é prática comum a aplicação de sanções disciplinares por quaisquer faltas ou atrasos, mesmo para as faltas justificadas legalmente.

Os trabalhos de fiscalização, que ora são relatados, foram conduzidos nos respectivos estados de acordo com as peculiaridades regionais.

Na Delegacia Regional do Trabalho do Rio Grande do Sul, em Porto Alegre, de 1999 a 2002, o Programa de Prevenção de LER/DORT realizou diversas vistorias em que foram encontradas variadas e numerosas irregularidades, ações relatadas em Peres (2005). Essas auditorias e os relatos bibliográficos apresentados por Peres (2005) apontam que os agravos à saúde de trabalhadores nos call centers são semelhantes nas diferentes modalidades de atendimento telefônico, sendo encontrados tanto em empresas não-informatizadas quanto em empresas que utilizam maior grau de informatização. Nessas inspeções, a terceirização foi observada como uma estratégia de redução de custos operacionais e, tal qual relatada nos estudos de caso de três empresas, piorou as condições de trabalho dos operadores e os expôs aos riscos ocupacionais com conseqüências para a saúde. Foram encontradas irregularidades diversas, tais como mobiliário inadequado, precárias condições de conforto, falta de condições para alimentação, não fornecimento de água potável, equipamentos de telefonia inadequados, climatização e ventilação inapropriadas, excessos ilegais de duração de jornadas. Em relação às tarefas executadas, constatou-se controle contínuo e estressante, a cada hora, das ligações, continuidade de movimentos repetitivos e de solicitação intelectual concentrada, conflitos e ambigüidade de tarefas e necessidade constante de superar outros operadores ou outras equipes. Essas constatações incluem ainda obrigações de gentileza com clientes a todo custo, seguimento obrigatório de expressões de scripts pré-determinados e cômputo rígido de pausas "improdutivas", como idas ao banheiro e lanches.

Da mesma forma, no Estado de Minas Gerais, outras auditorias fiscais vêm sendo realizadas em empresas que se ocupam do 
teleatendimento, especialmente naquelas que subcontratam serviços de atendimento ao público usuário de concessionárias de telefonia fixa e móvel. A situação encontrada não difere substancialmente daquelas observadas em outros estados, em que se fazem presentes altas taxas de rotatividade, população jovem e feminina com diversas queixas de saúde pouco reconhecidas, ambientes de trabalho deficientes e tentativas de minimização dos problemas por parte das empresas (MARINHO-SILVA \& ASSUNÇÃO, 2005).

O Ministério Público do Trabalho em Minas Gerais abriu inquérito civil público a partir dos relatórios de fiscalização envolvendo sete empresas do setor e propôs termo de ajuste de conduta cujo texto tem como base estudos acadêmicos e aqueles efetuados pela Comissão Nacional de Ergonomia do MTE. Esse processo foi relatado em Marinho-Silva (2004), sendo posição unânime das empresas envolvidas, até o momento, a recusa de assinatura do termo de ajuste, considerando que, a seu ver, não vêm cometendo qualquer irregularidade passível de sanção. Esse longo processo, durando já mais de 5 anos, envolve a colaboração da Universidade Federal de Minas Gerais, que desenvolveu profundo estudo sobre as formas de trabalho e os controles sobre trabalhadores utilizados em centrais de atendimento. Durante as audiências públicas realizadas com as empresas, diversas intervenções empresariais procuravam turvar o processo, incluindo a tentativa de impugnação do trabalho da Procuradora do Ministério Público do Trabalho, com alegações de quebra de sigilo empresarial na divulgação pública do processo. $\mathrm{O}$ impasse jurídico surgido deverá evoluir para uma ação civil pública, conforme relatos dos procuradores envolvidos.

No Rio de Janeiro, foi realizada fiscalização intensiva de 32 centrais de atendimento telefônico de pelo menos 21 empresas no período de julho de 2003 a dezembro de 2004 no âmbito do Projeto de Prevenção da LER/DORT, atual Projeto Ergonomia. Foram elaborados dois termos: um de notificação, específico para as situações de trabalho observadas no teleatendimento/telemarketing, e outro termo com os parâmetros mínimos para elaboração da análise ergonômica do trabalho, este último com base no Manual de Aplicação da NR-17 elaborado pela CNE.

A seleção das empresas fiscalizadas incluiu demandas variadas: denúncias de trabalhadores portadores de DORT, denúncias de sindicatos dos trabalhadores e do Ministério Público do Trabalho, que teve papel relevante, à semelhança do estado de Minas Gerais, na regularização de itens constantes em relatórios de fiscalização por meio de termos de ajustamento de conduta.

Na Delegacia Regional do Trabalho de São Paulo, as denúncias de operadores de telemarketing acometidos por DORT fizeram com que o Programa Estadual de Ergonomia convidasse o sindicato dos trabalhadores (Sindicato dos Trabalhadores em Telemarketing e Rádio-Chamada - SINTRATEL) e o sindicato dos empregadores do setor de telemarketing (Sindicato das Empresas Prestadoras de Serviços e Telemarketing - SINTELMARK) para negociação coletiva tripartite. Foram realizadas reuniões mensais no período de agosto de 2002 a junho de 2003. O SINTRATEL apresentou documento elaborado pela entidade relatando o acometimento de trabalhadores por problemas de voz, lesões por esforços repetitivos e problemas psicológicos. Foram também solicitados a colaborar como assessores vários profissionais dos Centros de Referência de Saúde dos Trabalhadores e da Universidade de São Paulo.

Um dos primeiros pontos de discussão do grupo tripartite foi a abrangência da regulamentação pretendida, sendo caracterizada sua aplicação para os códigos 4223 ("operador de telemarketing”) e 4201 ("supervisor de telemarketing e atendimento”) da Classificação Brasileira de Ocupações. À época, o grupo de trabalho tripartite definiu que cada sindicato indicasse 10 empresas para serem inspecionadas com o objetivo de definir um diagnóstico da situação. Os auditores fiscais do trabalho com formação em Medicina e Engenharia, participantes do "Programa Estadual de Ergonomia”, elaboraram roteiro de inspeção e vistoriaram empresas indicadas, verificando situações de trabalho que corroboram as descrições de auditores das outras delegacias regionais.

Durante esse processo de diagnóstico da situação, surgiram problemas relacionados com a questão da representação legal dos trabalhadores, já que alguns eram vinculados ao SINTRATEL e outros ao Sindicato dos Trabalhadores de Telefonia (SINTTEL). Diante desses problemas e pelo início das reuniões da Comissão Nacional de Ergonomia com representantes dos empregadores e trabalhadores, optou-se pela desativação 
daquele processo de negociação local, privilegiando-se a participação de técnicos e entidades nas discussões nacionais. $\mathrm{Na}$ Delegacia Regional do Trabalho, continuaram sendo realizadas inspeções mediante denúncias específicas, sempre com a demonstração de que os aspectos da organização do trabalho eram os mais difíceis de serem modificados.

Esse tipo de fiscalização encontra dificuldades similares em todos os estados. A começar pela própria localização das empresas, uma vez que as empresas especializadas em telemarketing não se classificam em códigos de CNAE - Classificação Nacional de Atividades Econômicas - do setor telefônico. Esse fato gera grande resistência dos empregadores para acatar as reco- mendações da fiscalização. Alega-se que os parâmetros previstos na NR-17 não seriam específicos para a atividade de teleatendimento, levando a embates e discussões na ação fiscal, tanto com profissionais da área de segurança e saúde quanto com representantes dos setores jurídicos das empresas. Deve ser destacado o posicionamento dos empresários, entendendo que o trabalho em teleatendimento não geraria qualquer risco à saúde dos trabalhadores, como demonstrado em Marinho-Silva (2004).

Tais fatos, confirmados e corroborados pela observação em outros estados da Federação, já apontavam, desde então, para a necessidade de um dispositivo legal específico para esse setor econômico.

\section{A construção social da norma para o teleatendimento}

Ao final da década de 1990, em paralelo aos programas de inspeções nos estados, o crescimento do número de doenças ocupacionais relacionadas à intensificação do trabalho e à precarização das relações de emprego, aliado às pressões de diferentes setores (Ministério Público do Trabalho, Previdência Social, Sindicatos) para que se incentivasse a fiscalização da aplicação da NR-17, levou o Ministério do Trabalho e Emprego a implementar uma coordenação nacional das ações em ergonomia no âmbito de suas competências, sendo estruturada a Comissão Nacional de Ergonomia (CNE).

De imediato, constatou-se a necessidade de atualização técnica para auditores fiscais, o que levou ao desenvolvimento de amplo processo de capacitação, que envolveu um grupo de instrutores do próprio MTE (auditores e pesquisadores da Fundacentro), articulado com a Associação Brasileira de Ergonomia. Entre 2000 e 2001 foram capacitados aproximadamente 450 engenheiros, médicos do trabalho e técnicos de segurança de todas as delegacias regionais do trabalho (OLIVEIRA et al., 2004).

Adicionalmente, o impacto das novas tecnologias sobre a atividade dos trabalhadores em contato telefônico foi abordado pela CNE em eventos nacionais com a participação de representantes de empregadores, empregados e universidade a partir das crescentes demandas dos atores envolvidos, especialmente a partir de solicitação formal da Federação Interestadual dos Tra- balhadores em Empresas de Telecomunicações (FITTEL) ao MTE em 2002.

Entre os eventos realizados destaca-se o painel "Novas atividades e velhas doenças: o trabalho em teleatendimento", realizado no I Seminário Integrado de Pesquisa e Pós-Graduação em Saúde do Trabalho, em 30 de setembro de 2002, em Porto Alegre, do qual participaram profissionais da DRT RS, da Universidade de São Paulo e do Sindicato dos Trabalhadores de Telefonia do Rio Grande do Sul.

No mesmo período, foi realizado o "Seminário Nacional sobre a Atividade de Teleatendimento/Telemarketing no Setor de Telefonia”, em São Paulo-SP, em outubro de 2002. O evento envolveu exposições sobre aspectos de saúde e ergonomia em teleatendimento e trabalhos em grupos, envolvendo representantes dos trabalhadores de vários estados do Brasil, bem como técnicos de empresas, pesquisadores da área e auditores fiscais de DRTs de todo o país. As recomendações dos grupos de trabalho formados nesse seminário serviram de base para elaboração da recomendação técnica posteriormente divulgada pelo Ministério do Trabalho e Emprego.

O encaminhamento da discussão do teleatendimento ao Fórum Social Mundial em 2003 estava dentre as sugestões propostas naquele seminário, tendo sido efetivado na Mesa Redonda "A realidade dos profissionais de teleatendimento/telemarketing”, da qual participaram profissionais dos sindicatos dos trabalhadores, da Universidade 
Federal de Minas Gerais e da Delegacia Regional do Trabalho do Rio Grande do Sul.

Em todas essas discussões, confirmouse que a maioria dos operadores brasileiros, assim como em outros países, é jovem e que são freqüentes as situações em que os desgastes físico e emocional acabam por comprometer o futuro profissional desses trabalhadores.

Mesmo com evidências fortes de adoecimento dos operadores e de necessidade de regulamentação do setor, o caminho para a construção de uma norma específica para as condições de trabalho tem apresentado várias dificuldades.

De um lado, o perfil dos trabalhadores mostra profissionais jovens, de bom padrão cultural, em geral no primeiro emprego, freqüentemente à procura de outra ocupação futura e que utilizam seus rendimentos para complementação de despesas com ensino e manutenção. As representações sindicais envolvidas são unânimes em afirmar a dificuldade de congregar e mobilizar trabalhadores dessa natureza, o que fragiliza a ação sindical e a própria atuação dos órgãos públicos de proteção à saúde ocupacional. As facilidades tecnológicas de comercialização de produtos e contatos por via eletrônica pela rede de Internet e a fragmentação do setor de telefonia, após a privatização dos serviços telefônicos no Brasil, a partir de 1998, levaram à existência de uma miríade de empresas de vários portes, prestadoras de serviços e vendas, que utilizam diretamente a interface telemática em sua rotina diária. Os trabalhadores dessas empresas não têm uma representação sindical homogênea, trazendo conflitos de representatividade, como aconteceu no estado de São Paulo durante as negociações tripartites. Essa situação enfraquece a força dos trabalhadores frente ao poder econômico das empresas.

De outro lado, as instituições públicas voltadas para a saúde do trabalhador não têm se manifestado de maneira direta e incisiva em busca de mudanças na situação atual. Em que pese a atuação do SUS, estruturando-se em todo o Brasil em centros, núcleos ou programas de saúde do trabalhador, utilizando equipes multidisciplinares, o acesso de trabalhadores a profissionais conhecedores dos riscos gerados pelo teleatendimento intensivo e preparados para orientar e intervir nas situações reais ainda é precário. As estatísticas de adoecimento no trabalho em nosso país vinculam-se à aceitação pelo INSS de situações de incapacidade evidente, que não são comuns na população jovem predominante no telemarketing e nos tipos de patologia gerados pelo setor, como são as alterações vocais, osteomusculares e os distúrbios mentais menores. Tratando-se de patologias relativamente inespecíficas, a subnotificação desses agravos à saúde leva a uma relativa invisibilidade da situação de saúde desses trabalhadores, dificultando, inclusive, a ação do Ministério Público do Trabalho, já que se torna difícil demonstrar à sociedade e ao judiciário os prejuízos causados pelo adoecimento dos teleatendentes.

Ainda de outra parte, os textos do órgão regulador da atividade de telefonia em nosso país - Agência Nacional de Telecomunicações (ANATEL) - não fazem qualquer referência à saúde dos trabalhadores envolvidos, tanto nas concessionárias quanto nos prestadores de serviços (MARINHO-SILVA, 2004). São regras focadas nos aspectos econômicos do setor, sendo o conceito de qualidade de atendimento vinculado basicamente aos tempos de espera do consumidor. Paradoxalmente, então, as exigências de "qualidade", traduzidas em redução de tempos do serviço telefônico prestado, acabam por justificar a definição de rígidos tempos médios de atendimento (“TMA") pelas empresas.

Essas empresas, grandes conglomerados multinacionais em sua maioria, empregam hoje centenas de milhares de jovens. Elas ostentam seu poder econômico inclusive frente às ações públicas, como ficou demonstrado durante as fiscalizações, por exemplo, quando uma das empresas demitiu todos os operadores do Rio Grande do Sul e transferiu suas atividades para o Estado de Goiás, e também nos inquéritos do Ministério Público do Trabalho, como mostrou Marinho-Silva (2004). A redução de custos é a tônica, fazendo com que o controle do tempo e das formas de atendimento seja item gerencial de primeira linha em empresas que, para sua lucratividade, dependem primordialmente do uso e custo de sua mão-de-obra direta. Assim, a discussão de pausas, redução de metas de produtividade, mais conforto e melhores condições de mobiliário, por exemplo, esbarram continuamente nos aspectos de custo.

Como resposta a esse movimento social envolvendo trabalhadores e suas entidades sindicais, universidades e profissionais do MTE, a Comissão Nacional de Ergonomia 
apresentou uma minuta de nota técnica relativa a telemarketing em um curso para auditores fiscais de todo o Brasil, em novembro de 2003, aprimorando o texto a ser apresentado ao Departamento de Saúde e Segurança do Trabalho (DSST) do MTE.

Em continuidade, o DSST constituiu, em 2004, um grupo interministerial reunindo representantes do Ministério da Saúde, do Ministério da Previdência Social, do Ministério Público do Trabalho e da Agência Nacional de Telecomunicações. Esse grupo elaborou o texto que foi divulgado na página de Internet do $\mathrm{MTE}^{6}$ como "Recomendação Técnica DSST $\mathrm{n}^{\circ}$ 01/2005", datado de 23 de março de 2005, sobre "Segurança e Saúde nas Atividades de Teleatendimento”.

Essa recomendação, a despeito de não ter sido publicada em Diário Oficial e de não possuir efeito de norma impositiva, teve ampla divulgação e gerou efeitos positivos, servindo como referência para inspeções do MTE, apontando para regimes de pausas de descanso antes inexistentes e também servindo de referência para acordos tripartites durante o ano de 2004, como o realizado no Rio Grande do Sul e publicado no jornal do Sindicato dos Comerciários de Porto Alegre (SINDEC).

Revistas especializadas em segurança do trabalho publicaram o texto da Recomendação, assim como se tornou disponível o arquivo digitalizado para cópias em páginas de Internet, especialmente de entidades sindicais da área de telefonia.

Entretanto, em 7 de junho de 2005, a Associação Brasileira de Telemarketing (ABT), associação empresarial do setor, fez divulgar em sua página eletrônica ${ }^{7}$ a notícia de que teria obtido do MTE a "suspensão da aplicabilidade” da RT 001/2005, manifestando "insatisfação e discordância" com o que entendeu como "medidas unilaterais", pleiteando ter "voz ativa nesse processo", manifestação feita em nome de 11 grandes empresas de teleatendimento.

As discussões que se seguiram levaram o MTE a optar pela formação de grupo técnico para a elaboração de proposta de anexo à Norma Regulamentadora 17 ("Ergonomia”), específico sobre o teleatendimento, conforme Portaria DSST/SIT/MTE n ${ }^{\circ} 148$ de fevereiro de 2006. O grupo, formado por auditores fiscais do MTE, técnicos da Fundacentro e membros do Ministério Público do Trabalho, desenvolveu texto técnico básico encaminhado à Comissão Nacional Tripar- tite Permanente, encarregada da aprovação de Normas Regulamentadoras em segurança e saúde no trabalho. Essa discussão levou à publicação da Portaria DSST/SIT/ MTE $n^{0} 153$, em 14 de março de 2006, que divulgou, para consulta pública de 60 dias, o texto técnico básico do Anexo II da NR-17 (Trabalho em Teleatendimento).

\section{A proposta de anexo à NR-17}

O potencial patogênico das condições de trabalho nos centros de teleatendimento foi descrito por diferentes estudos relatados na introdução deste artigo e tem sido verificado nas inspeções realizadas por auditores das Delegacias Regionais do Trabalho. Existe necessidade e urgência de regulamentação estatal acompanhada de políticas públicas para o setor de teleatendimento visando à aquisição de certo equilíbrio de forças entre quem organiza e comanda a produção e aqueles que, ao produzirem, sofrem a repercussão do trabalho (MARINHO-SILVA, 2004).

Várias orientações governamentais para boas práticas em centrais de teleatendimento, desenvolvidas com base na literatura técnica sobre o trabalho nessa atividade (HSE, 2006) ${ }^{8}$, estão disponíveis nos chamados países de "primeiro mundo".

Da mesma forma, diversos autores apontam formas de redução da carga física e mental de trabalho nas tarefas de telemarketing, como se aponta nos tópicos seguintes:

\section{Posto de trabalho (posturas de pé e sen- tado)}

Lips et al. (1991) recomendam organizar o trabalho de modo a alternar a atividade com monitores de vídeo com outras tarefas em que o trabalhador possa estar em pé ou movimentar-se ou, pelo menos, mudar a posição do corpo e interromper o trabalho no teclado (trabalho misto).

\section{Pausas no trabalho}

Taylor (1995), ainda no início do século, já reconhecia o prejuízo da fadiga e observou que "mesmo depois de reduzir as horas de trabalho de 10,5 para 8,5 ”, após hora e meia de serviço consecutivo, as moças "começavam a mostrar-se nervosas”. Para redução dos sinais de fadiga, estabeleceu pausa de dez minutos ao fim de cada hora e um quarto de trabalho. Peres (2003) estudou a satisfação dos operadores de uma empresa de telemarketing com o sistema de pausas implantado, mostrando
${ }^{6}$ www.mte.gov.br

${ }^{7}$ www.abt.org.br

${ }^{8}$ Ver também HEALTH \& SAFETY EXECUTIVE (HSE). Psychosocial risk factors in call centres: an evaluation of work design and well-being. 2003. Disponível em: http://www.hse. gov.uk/research/rrhtm/rr169.htm. No mesmo sentido, consultar também http://actu.labor.net. au/public/papers/minstandscode. html. 
${ }^{9}$ Texto integral disponível em http://www.mte.gov.br/Empregador/SegSau/Legislacao/Portarias/2006/conteudo/portaria153. pdf. evidências de insatisfação principalmente por parte dos operadores com maior tempo de serviço, constatando "baixa motivação" e "alta pressão psicológica” em entrevistas. As pausas (cinco minutos durante a jornada) não eram compatíveis com a natureza de suas tarefas e não atendiam às exigências da NR-17 do MTE para processamento eletrônico de dados.

Kopardekar e Mital (1994), estudando configurações de pausas em operadores telefônicos, recomendaram pausas de 10 minutos após 60 minutos trabalhados. Essa recomendação é consistente com os achados de Ferreira et al. (1997), que mostraram o efeito positivo de pausas de 10 minutos após 50 minutos de trabalho na redução do número de casos de distúrbios osteomusculares relacionados ao trabalho.

Participação dos trabalhadores nas definições de metas de tempo e produção

DiTecco et al. (1992) encontraram como maior fonte de estresse em operadores os itens de pressão de tempo para atendimento: $70 \%$ declararam dificuldades em atender bem um cliente e manter baixo tempo de atendimento e 55\% dos operadores relataram que o monitoramento telefônico contribui para a sensação de estresse no trabalho.

\section{Dimensionamento do número de opera- dores adequado à demanda}

Glina e Rocha (2003) mostraram que a presença de fila de espera em centros de atendimento levava à realização de horas extras, intensificação do trabalho, manutenção das mesmas posturas e tensão dos operadores. A pressão sobre os trabalhadores aumentava com a irritação dos clientes após a espera, a existência de displays eletrônicos informando o número de clientes em espera e a postura dos supervisores exigindo aceleração no processo de atendimento.

\section{Considerações finais}

Este artigo documenta a construção coletiva de normatização para uma ocupação. Deste processo participaram órgãos públicos, instituições de ensino, representação dos trabalhadores e empregadores, trazendo conhecimentos para o estabelecimento de normas e procedimentos que não permitam que o trabalho dos operadores de telemarketing seja responsável pelo adoe-
Os temas incluídos na recomendação técnica e no texto ora em discussão como anexo da NR-1 $7^{9}$ foram desenvolvidos a partir das queixas dos trabalhadores, das observações das principais inconformidades verificadas nas ações fiscais e em dados de literatura científica, referindo-se, em linhas gerais:

- ao mobiliário dos postos de trabalho;

- aos equipamentos dos postos de trabalho;

- aos sistemas telefônicos e informáticos;

- às condições ambientais de trabalho, incluindo ruído e climatização;

- à organização do trabalho, incluindo:

- contingente de operadores

- pausas adequadas ao tipo de atendimento

- liberdade de saída dos postos de trabalho

- possibilidade de alternância de postura

- metas de produção discutidas com os trabalhadores e mais flexíveis

- redução da monitoração por gravação e escuta

- proibição de incentivos monetários à produção

- redução de pressões de tempo

- redução de monitoria por escuta e gravação

- à capacitação dos trabalhadores;

- às condições sanitárias e de conforto;

- aos Programas de Controle Médico de Saúde Ocupacional (PCMSO) e de Prevenção de Riscos Ambientais (PPRA);

- às análises ergonômicas do trabalho;

- à facilitação para pessoas portadoras de deficiência.

cimento dos trabalhadores e que possibilitem às pessoas exercer esta atividade por toda uma vida profissional.

A proposição de norma regulamentadora sobre a atividade dos operadores de teleatendimento/telemarketing é justificada pelas situações de trabalho encontradas, expondo os trabalhadores a fatores de risco 
de adoecimentos físico e mental. O estudo destaca o reconhecimento às queixas dos trabalhadores, trazidas por suas representações, sobre suas condições de trabalho e adoecimento, conhecimentos utilizados como instrumentos técnico e político para buscar a modificação dos ambientes e da própria organização do trabalho.

Neste estudo verificou-se que intervenções que contrariam a força e a lógica

\section{Referências bibliográficas}

ABRAHÃO, J. I. Reestruturação produtiva e variabilidade do trabalho: uma abordagem da ergonomia. Psic.: Teor. e Pesq., v. 1, n. 16, p. 49-54, 2000 .

ABT. Associação Brasileira de Telemarketing. Página de abertura. Disponível em: http://www.abt.org.br. Acesso em: 10 set. 2005.

ASSUNÇÃO, A. A.; SOUZA, R. Telemática. São Paulo: INST/CUT, 2000. (Cadernos de Saúde do Trabalhador, 11).

ASSUNÇÃO, A. A.; VILELA, L. V. O. As condições de adoecimento em uma empresa de teleatendimento. Belo Horizonte: Editora Faculdade de Medicina UFMG, 2003. Relatório de pesquisa.

BARRETO, F. L. O sofrimento psíquico e o processo de produção no setor de telefonia: tentativa de compreensão de uma atividade com caráter patogênico. 2001. Dissertação (Mestrado em Engenharia de Produção) - Faculdade de Engenharia de Produção, Universidade Federal de Minas Gerais, Minas Gerais, 2001.

BROUGHTON, K.; PATEL, J. A. Noise exposure levels in call centres. Proceedings of the Institute of Acoustic, v. 25, part 4, p. 211-216, 2003.

CFDT. CONFÉDÉRATION FRANÇAISE DÉMOCRATIQUE DU TRAVAIL. Centres d'appels. Enquête. Disponível em: http:// www.cfdt.fr. Acesso em: set. 2002.

DEJOURS, C. A Loucura do trabalho: estudo de psicopatologia do trabalho. Tradução Ana Isabel Paraguay e Lúcia Leal Ferreira. 5 ed. São Paulo: Cortez/Oboré, 1992.

DITECCO, D. et al. Operator stress and monitoring practices. Appl. Ergon., v. 23, n. 1, p. 29-34, 1992.

FERNANDES, S. R. P.; DI PACE, D. M. T.; PASSOS, M.F.D. Organização e con- econômica encontram imensas dificuldades em sua trajetória, destacando que os desafios para a melhoria das condições de trabalho e saúde dos trabalhadores estão condicionados às conjunturas econômicas, políticas e à participação dos diferentes atores sociais. Somente o amplo apoio social, baseado na organização dos trabalhadores e nas políticas públicas, poderá se contrapor às situações de trabalho predatórias instaladas.

dições de trabalho em "telemarketing": repercussões na saúde psíquica dos trabalhadores. In: JACQUES, M. G.; CODO, W. (Orgs.). Saúde Mental e Trabalho: leituras. Petrópolis: Vozes, 2002. p. 247-270.

FERREIRA Jr., M.; CONCEIÇÃO, G. M. S.; SALDIVA, P. H. N. Work organization is significantly associated with upper extremities musculoskeletal disorders among employees engaged interactive computertelephone tasks of an International Bank subsidiary in São Paulo, Brazil. Am. J. Ind. Med., v. 31, n. 4, p. 468-473, 1997.

FERREIRA Jr., M.; SALDIVA, P. H. N. Computer-telephone interactive tasks: predictors of musculoskeletal disorders according to work analysis and workers' perception. Appl. Ergon., v. 33, n. 2, p. 147-153, 2002.

GLINA, D. M. R.; ROCHA, L. E. Fatores de estresse no trabalho de operadores de centrais de atendimento telefônico de um banco de São Paulo. Revista Brasileira de Medicina do Trabalho, v. 1, n. 1, p. 31-39, 2003.

HALES, T. R. et al. Musculoskeletal disorders among visual display terminal users in a telecommunications company. Ergonomics, v. 37, n. 10, p. 1603-1621, 1994.

HOEKSTRA, E.; HURRELL, J.; SWANSON, N. Evaluation of work-related musculoskeletal disorders and job stress among teleservice center representatives. Applied Occup. Environ. Hygiene, v. 10, p. 812-817, 1995.

HSE. HEALTH \& SAFETY EXECUTIVE (HELA). Advice regarding call centre working practices. Available from: http://www. hse.gov.uk/lau/lacs/94-2.pdf. Access: 01 jan. 2006.

INRS. INSTITUT NATIONAL DE RECHERCHE ET DE SÉCURITÉ. Travail en centres d'appels téléphoniques. 2005. Disponível 
em: http://www.inrs.fr. Acesso em: 20 jan. 2006.

KOPARDEKAR, P.; MITAL, A. The effect of different work-rest schedules on fatigue and performance of a simulated directory assistance operator's task. Ergonomics, v. 37, p. 1697-1707, 1994.

LE GUILLANT, L. et al. A neurose das telefonistas. Rev. bras. saúde ocup., v. 12, n. 47, p. 7-11, 1984.

LIPS, W. et al. Le travail à I monitor de visualisation. Caisse Nationale Suisse dÀssurance en Cas d Accidents. Lisboa: Instituto de Desenvolvimento e Inspeção das Condições de Trabalho, 1991.

MARINHO-SILVA, A. A regulamentação das condições de trabalho no setor de teleatendimento no Brasil: necessidades e desafios. 2004. Dissertação (Mestrado em Saúde Pública) - Faculdade de Medicina, Universidade Federal de Minas Gerais, Minas Gerais, 2004.

MARINHO-SILVA, A.; ASSUNÇÃO, A. A. Negociações sociais para melhoria das condições de trabalho no setor de teleatendimento: o descompasso entre a posição das empresas e a realidade do trabalho. Interface-Comunic., Saúde, Educ., v. 9, n. 18, p. 553-570, 2005.

OGREN, F. et al. Prevalence and risk factors for voice problems among telemarketers. In: AMERICAN ACADEMY OF OTOLARYNGOLOGY-HEAD AND NECK SURGERY FOUNDATION ANNUAL MEETING, 2001, Denver. Available from: http://www. newswise.com/p/articles/view/25784. Access: jan. 2006.

OLIVEIRA, P. A. et al. Comissão Nacional de Ergonomia e políticas públicas: a implementação de procedimentos auxiliares à NR 17 (os casos da indústria de calçados, de telemarqueting, de supermercados e de abate e processamento de carnes). In: CONGRESSO BRASILEIRO DE ERGONOMIA, 13, 2004, Fortaleza. Anais... Fortaleza: ABERGO, 2004. 1 CD.

PERES, C. C. Avaliação da satisfação com o sistema de pausas no trabalho de teleatendimento/telemarketing. 2003. Dissertação (Mestrado em Ergonomia) - Escola de Engenharia, Universidade Federal do Rio Grande do Sul, Porto Alegre, 2003.

. Ações coletivas para prevenção de LER/DORT. Boletim da Saúde, v. 19, n. 1, 2005.

ROCHA, L. E. et al. Risk factors for musculoskeletal symptoms among call center operators of a bank in São Paulo, Brazil. Ind. Health, v. 43, n. 4, p. 637-646, 2005.

TAYLOR, F. W. Princípios de administração científica. Tradução Arlindo Vieira Ramos. São Paulo: Atlas, 1995.

TOOMINGAS, A. et al. Working conditions and employee health at call centers in Sweden. Stockholm: National Institute for Working Life, 2002.

UNISON. Voice loss threatens workers. News, sep. 2005. Available from: http:/ www.unison.org.uk/news/news_view. asp?did=2070. Access: 20 jan. 2006.

VILELA, L. V. O.; ASSUNÇÃO, A. A. Os mecanismos de controle da atividade no setor de teleatendimento e as queixas de cansaço e esgotamento dos trabalhadores. Cad. Saúde Pública, v. 20, n. 4, p. 10691078, 2004.

WISNER, A. A inteligência do trabalho: textos selecionados de ergonomia. Tradução Roberto Leal Ferreira. São Paulo: Fundacentro, 1994. 